\title{
The peculiarities of artillery officers' practical thinking development
}

\author{
I. Moskalov \\ Doctoral Student, National Defence University of Ukraine named after Ivan Cherniakhovskyi, Humanitarian Institute, Department of \\ Social Science, Kyiv, Ukraine \\ Corresponding author. E-mail: i_moskalyow@ukr.net, ORCID ID:0000-0001-7950-1120
}

Paper received 02.05.19; Accepted for publication 15.05.19.

https://doi.org/10.31174/SEND-PP2019-198VII80-16 Abstract. The paper deals with results of empirical study aimed to determine peculiarities in accordance with defined compounds of
thinking process of military professionals, namely artillery officers. The main aim of the study was to investigate whether representa-
tives of the specific particular speciality while receiving the military degree, their professional activity generated and developed some
compounds of thinking processes. The Intelligence Structure Test by Amthauer was used as a diagnostic tool as its allowed to resolve
intelligence into substructures (verbal, mathematical, dimensional, mnemic).

Keywords: intelligence, practical thinking, development, sample, psychological assessment, officer-artillerist, similarity, difference.

Introduction. Development of military arts, constant improvement and finding of new forms and methods of militant actions set new requirements for training of military professionals of relevant army fields. We can observe a high level of labor differentiation, shortening of training periods, the emergence of new professionals, severization of requirements for the training of professionals.

It is notorious that one's psychic and psychophysiological properties can be developed and improved in the process of education, training, special training, others are relatively stable and require considerable time for the improvement and development, and third ones, for example, the typological characteristics of higher nervous activity, temperament, etc., can save personality traits and features throughout life [4, c. 7; 10, c. 120-125].

The modern psychological science has such achievements as a diagnostic tool for professional and psychological selection of military professionals in accordance with military speciality. The essential condition for successful activity is a developed practical thinking. Some scientists define practical thinking in relation to the specific occupation as professional thinking. However, this article concerns practical thinking, as an instrument for solving practical problems that arise in the process of professional activity.Thinking is a complex and integral concept, many factors influence on mental processes, namely: emotional state, motivational orientation, level of intelligence, previous experience, etc.[5, c. 325; 6, c. 36]. In our study, we focus on the development of the intellectual component of practical thinking within a separate military specialty.

At the present stage of research of intelligence and thinking we should make a point of works of K. Abul'khanovoyi-Slavs'koyi, A. Brushlins'koho, V. Davydova, D. Zavalyshynoyi, M. Kashapova, V. Klimenka, Yu. Kornilova, T. Kudryavtseva, S. Maksymenka, V. Molyaka, I. Pasichnyka, M. Smul'son, M. Kholodnoyi and other.There are studies of S. Maksimenko, V. Molyako, G. Nagornoy, S. Symonenko, O. Tikhomirova, V. Yagupova dealing with specific types of professional thinking of production managers, designers, doctors, operators, teachers, practical psychologists.

The goal of the study: Determination of the levels of development of individual components of thinking depending on the peculiarities of specific militaryprofessional activities.
Own studies. We have organized and held an experiment on the basis of National Defense University named after Ivan Cherniakhovskyi (further - University). The aim was to research whether some components of thinking processes of representatives of specific military specialties in the process of certain military education, professional activity formed and developed or vice versa collapsed. The essence of the experiment was comparative correlative study of two randomized groups (R1 and $\mathrm{R} 2$ ) in order to find similarities or differences in certain components of mental processes.

The comparative correlation study represents a matrix of correlations that reveals the structure of relationships between variables. For different types of measurement of data $\mathrm{X}_{\mathrm{i}}$ correlation coefficients are calculated only after $\mathrm{Z}$ changes: $\mathrm{Z}=\left(\mathrm{X}_{\mathrm{i}}-\mathrm{X} / \sigma\right)$, where $\mathrm{X}$ - average, $\sigma-$ standard deviation[9, c. 50].

Candidates for admission to the University in 2017 were a sample $(n=184)$. The sample was formed taking into account all necessary criteria. So this sample can be representative towards statistical universe - students of National Defence University of Ukraine named after Ivan Cherniakhovskyi. According to the aim of the study the sample was divided into two groups. Group 1 (R1) consisted of students $(n=96)$ of all specialties of the Humanitarian Institute of the University. In particular, it is necessary to describe the features of the control group and the requirements for it. The main requirement was heterogeneity, the sample of students of the Humanitarian Institute should correspond to the general population, which is typical for average officer of the operational-tactical link of the Armed Forces of Ukraine of any specialty and kind of troops. Group 1 (R1) consisted of students of the $\mathrm{Hu}-$ manitarian Institute of the University, specializing in: "Personnel Management in the Troops (Forces)", "Organization of Moral and Psychological support of Troops (Forces)", "Organization of Psychological Support of Troops (Forces)", "Organization of Information and Propaganda Support Troops (Forces) ". The common aspects for these specialties are:

professionals of these specialties are not trained (or very few are trained) at the HMEI;

in the process of military service (military authorities), taking into account the realities and the necessity of the office, the above-mentioned specialties are completed by 
officers who have got a completely different education (command, technical and humanitarian) at the HMEI;

students of the aforementioned specialties of the $\mathrm{Hu}-$ manitarian Institute of the University, in the majority of cases, do not have previous higher education of chosen by them specialty;

in general, the activity of professional in these specialties has a more general approach and requires proportional development of all components of mental processes.

The variability of the sample for Group 1 of this experiment is following:

students of the control group are graduated from different HMEI and obtained different specialties of all types of armed forces and military branches;

$96 \%$ of students do not have previous higher military education in the current specialty, so they changed it in the process of their activity (for example, mechanized platoon commander for deputy company commander for moral and psychological support);

this sample is represented by both servicemen and servicewomen, their age - from 27 to 47 years, about $80 \%$ of all are combat veterans;

the multifunctional nature of these specialties representatives activity, which has to be acquainted with all other military fields and requires a general high level of education in the military sphere.

So, the abovementioned suggests that based on the results of empirical studies in the Group 1, we will have certain general indicators of the development of individual components of practical thinking in general for the averages student of the University.The Group 2 includes representatives of specific military specialty and data was obtained in the same way as in Group 1.

Students of the Command-and-Staff Institute of the Troops (Forces) Combat Use in specialty "Combat Employment and Management of Missile Troops and Artillery Units Combat Actions" were chosen for participation in the experiment as representatives of such specific military speciality». The main requirement for the Group 2 (B) was homogeneity, especially with regard to obtained vocational education and military service at the positions related to the acquired education.

The Group 2 (B) consisted of 87 students $(n=87)$ of the Command-and-Staff Institute of the Troops (Forces) Combat Use in specialty "Combat Employment and Management of Missile Troops and Artillery Units Combat Actions". This group has following peculiarities: all representatives of this group has professional education acquired in the HMEI, namely Military Institute of Missile Troops and Artillery under Sumy State University, according to the one curricula; all representatives served in a position of command staff in specialty "Combat Employment and Management of Missile Troops and Artillery Units Combat Actions"; all representatives are men between age of 32 and 45, representants of the same military branch and branch of the armed forces.

There are some peculiarities of artillery officer practical activity:

a great amount of mathematical problems (according to the demands of "Rules of Firing and Control of Land Arms of the Armed Forces of Ukraine" from 2018, artillery officer spends for solution of artillery (mathematical) problems about 18 hours during four working days per week )[3, c. 231-234; 6, c.24];

artillery officer invest a lot of efforts to work with graphic documents (maps, schemes, tables, graphs and other);

according to the demands of the training while solving any problems, the officer is limited by such characteristics : task-performance time, accuracy of calculation of initial firing data, amount of introduced errors (additionally they can be divided into critical and uncritical), and it is an extra stress-factor and it has a significant impact on progress and further development of thinking processes[3, c. 32].

In accordance with abovementioned, we can assume, that higher level of development of certain components of thinking due to the specifics of professional activity is typical to experimental group. It is expected to possess a higher level of development of thinking processes in relation to handling with mathematical and spatial images in case of artillery officers (working hypothesis $\mathrm{H}_{1}$ ). The absence of statistically essential difference on the level(p $=0.05$ ) will witness about confirmation of the nullhypothesis $\left(\mathrm{H}_{0}\right)$.

The Intelligence Structure Test by Amthauer was used as a diagnostic tool during the research. Intelligence is a relatively independent, dynamic structure of the cognitive characteristics of a person arising on the basis of genetic and congenital anatomical and physiological features of the brain and the nervous system, which is formed and shown in activity, caused by cultural-historical conditions and provides an adequate interaction with the surrounding reality, its purposeful transformation [2, c. 78]. The Intelligence Structure Test by Amthauer was used as a diagnostic tool during the research [8, c. 342-370], which considers the intelligence as a substructure in the integral structure of the individual. This structure is an ordered whole mental ability, which is formed and manifested in the activity. R. Amthauer identified four leading factors of thinking: verbal, mathematical, spatial, and mnemonic. There are 9 subtest methods in order to diagnose and direct 9, namely:

subtest 1 - on general awareness in various fields of knowledge (notonlyscientific);

subtest 2 - on classification of concepts;

subtest 3 - on establishment of analogies;

subtest 4 -on generalization;

subtest 5 -on solving of simple arithmetical problems; subtest 6 - on ability to find numeric peculiarities;

subtest 7 - on ability to operate with images (figures) in mind on a plane;

subtest 8 - on ability to operate with images of solids in mind;

subtest 9 - on learning words. [1, c. 208]

The Intelligence Structure Test by Amthauer allows to interpret results on four stages:

1. General level of intelligence. It is evaluated on the level of general score, received as a result of summing for every subtest and interpreted into standard index. Standartization was held on the sample 4076 and average rate of raw score is 82 . The reliability of test is 0,97 (correlation of paired and unpaired tasks), in case of re-testing a year after coefficients of reliability are equal 0,83 (in some 
subtest 0,50$)$. The validity of test upon criterion of education success is equal to 0,62 [1, c. 208].

2. Interpretation of the subtest group close by the factor principle. The subtest structure allows to evaluate in a nuanced way level of thinking sides' development. Some subtest can be defined in such groups:

a) complex of verbal subtests (subtest 1-4), that determine general ability to operate words as signals and symbols;

The verbal intelligence prevail in case of high results of this complex, the general commitment to social sciences and learning of foreign languages.

b) complex of mathematical subtests $(5,6)$, that defines abilities in the sphere of practical mathematics and software engineering. This results speak for "mathematical talent". This is an essential part of practical thinking of artillery officer.

c) complex of constructive subtests $(7,8)$, that determine developed constructive (spatial) abilities of theoretical and practical plans.

However, the high results for subtests of this complex is an important background not only technical, but also general scientific talent.

d) memory (mnemic abilities) (9) perception of word (and also memorizing) is a complicated process of including in the system of known codes, in which leading features are dominant and by-passing, subordinate features are pushed aside. This means, that the process of selection of leading connection system and suppression of auxiliary connections in the process of word fixation.

The fact of multidimensional connections of the word is significant because of its remembering. Remembering is a complex process of active search and choosing of necessary connection from many possible. This process is proceeding on the sidelines of suppression of lateral, nonessential components.

According to the results of this subtest we can see level of short-term memory development. This results can not be applied to level of memory development in general, because different types of memory are independent one from another.

3. In order to generalize "mental profile" R. Amthauer proposed the following: if 1-4 subtests shows the highest results, then the person has more developed theoretical abilities; if the person shows the highest results for five last subtests, then practical abilities are more developed. We took into consideration practical component, because of commitment to result of activity, but also the theoretical component shouldn't be ignored.

4. Interpretation of results of each subtest. The structure of intelligence profile construction.

So, the Intelligence Structure Test by Amthauer is suitable for use in our study and is valid, representative, tested, structured, and allows to process data in any convenient form (separately for each subtest, by factor subgroups, due to the direction of theoretical and practical abilities and entirely).

However, it is incorrect to consider thinking and intelligence as the same. It is worth to mention that any test for intelligence is not a guarantee of successful determination of human progress in professional activities.
So, P. Thorndike and E. Hagen, conducted a research; 10,000 people were searched 13 years after they had been tested, on the basis of which they were predicted about their success in the work. Authors collected data for 125 groups of profession and analyzed the connection between prediction, which were based on the test results and real achievements in the chosen profession. The conclusion was made that there is no connection between test results and professional success. Correlation is basically low, there are equally often occurrence of positive and negative meanings. In general, researchers got a coefficient of validity close to zero. Due to this information authors emphasize, that the most reliable results show substantiation of test profile indicating a certain expressiveness of individual abilities (for example, for accountants natural is a large expression of account capabilities, for architects - visual, for engineers - general [11, p. 78]. Thus, it is inappropriate to take into account the general level of intelligence while data processing. The analysis will be conducted by subtest groups and for each subtest separately with the withdrawal of the profile in our study.

The intelligence determines such peculiarities of the realization of the thinking process, such as speed, accuracy of the tasks, persistence in finding the right solution. At the same time, intelligence develops in the process of thinking.

The empirical material was processed in order to check our statistical hypothesis. In order to check statistical hypothesis of the average difference $(\mu 1-\mu 2)$ for interval data, which has normal law of distribution and unknown distribution law and unknown dispersion. We used Stu-

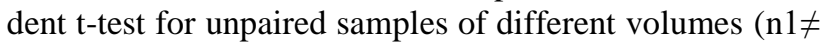
$\mathrm{n} 2$ ). The processing of the results was carried out at all three levels of R. Amthauer test mentioned in the article above:

1. General level of intelligence.

For group 1, average composite score by test $\mu 1=$ 93,19 , for group $2 \mu 2=95,03 . \mathrm{t}_{\mathrm{emp}}=-1,62, \mathrm{t}_{0,05}=1,65$, $\mathrm{t}_{0,01}=2,35$. While $\quad\left|\mathrm{t}_{\mathrm{emp}}\right|<\left|\mathrm{t}_{0.05}\right|<\left|\mathrm{t}_{0.01}\right|$ ( $|1,62|<|1,65|<|2,35|$ ), we accept a partial null hypothesis, that is, the two groups do not have statistically significant differences in the general level of intelligence Taking into consideration this fact, we can investigate whether in the group 2 separate components of intelligence (thinking) formed under the influence of professional activity.

2. Interpretation of subtests' group, close by the factorial principle introduced in the graph 1 and table 2 .

Graph 1. The comparative analysis of average values close by the factorial principle in the structure of intelligence among participants of the research

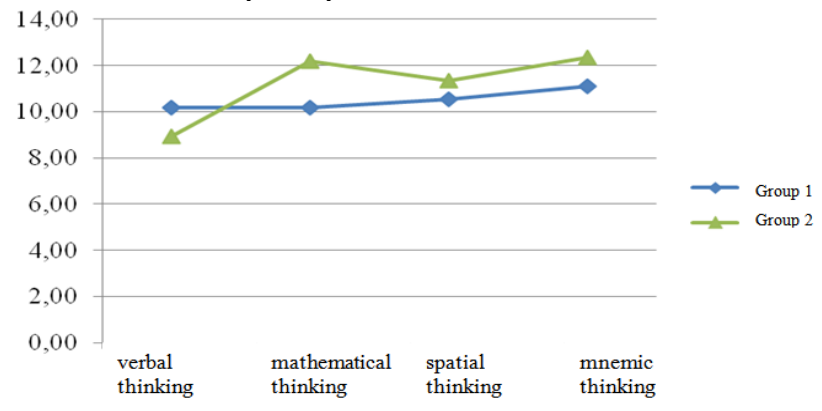


Table 2. The analytical table of comparative statistics among the two groups of subjects

\begin{tabular}{|l|c|c|c|c|}
\hline & $\begin{array}{c}\text { Verbal } \\
\text { thinking }\end{array}$ & $\begin{array}{c}\text { Mathematical } \\
\text { thinking }\end{array}$ & $\begin{array}{c}\text { Spatial } \\
\text { thinking }\end{array}$ & $\begin{array}{c}\text { Mnemic } \\
\text { thinking }\end{array}$ \\
\hline Group 1 $(\mathrm{n}=96)$ & 10,17 & 10,16 & 10,54 & 11,09 \\
\hline Group 2 $(\mathrm{n}=87)$ & 8,92 & 12,17 & 11,34 & 12,34 \\
\hline $\mathrm{t}_{\mathrm{t} m p}$ & 8,48 & $-9,93$ & $-3,83$ & $-4,20$ \\
\hline $\mathrm{t}_{0}, 05$ & 1,65 & 1,65 & 1,65 & 1,65 \\
\hline $\mathrm{t}_{0,01}$ & 2,57 & 2,53 & 2,54 & 2,52 \\
\hline Conclusion & $\begin{array}{c}\mu 1>\mu 2 \\
(\mathrm{p}=0,01)\end{array}$ & $\begin{array}{c}\mu 1<\mu 2 \\
(\mathrm{p}=0,01)\end{array}$ & $\begin{array}{c}\mu 1<\mu 2 \\
(\mathrm{p}=0,01)\end{array}$ & $\begin{array}{c}\mu 1<\mu 2 \\
(\mathrm{p}=0,01)\end{array}$ \\
\hline
\end{tabular}

3. Interpretation of results of each subtest. The structure of intelligence profile construction presented on Graph 2 and in the Table 3.
Graph 2. The comparative analysis of average values for each subtest in the intelligence structure among subjects

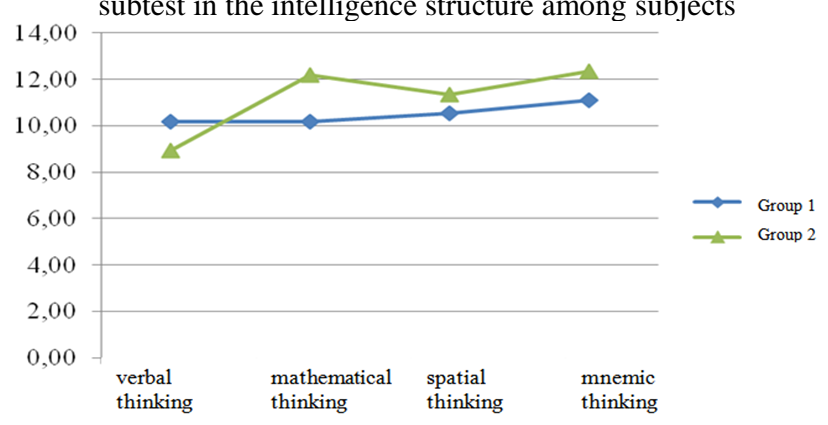

Table 3. Analytical table of comparative statistics among the two groups of subjects

\begin{tabular}{|l|c|c|c|c|c|c|c|c|c|}
\hline & \multicolumn{7}{|c|}{ № subtest } \\
\cline { 2 - 10 } & 1 & 2 & 3 & 4 & 5 & 6 & 7 & 8 & 9 \\
\hline $\begin{array}{l}\text { Group 1 } \mu 1 \\
(\mathrm{n}=96)\end{array}$ & 11,15 & 9,66 & 9,08 & 10,81 & 8,84 & 11,47 & 10,45 & 10,64 & 11,09 \\
\hline $\begin{array}{l}\text { Group 2 } \mu 2 \\
(\mathrm{n}=87)\end{array}$ & 8,98 & 8,97 & 7,68 & 10,05 & 10,91 & 13,43 & 11,18 & 11,51 & 12,34 \\
\hline $\mathrm{t}_{\text {emp }}$ & 7,62 & 2,23 & 5,05 & 3,45 & $-7,06$ & $-6,69$ & $-2,39$ & $-2,78$ & $-4,20$ \\
\hline $\mathrm{t}_{0,05}$ & 1,65 & 1,65 & 1,65 & 1,65 & 1,65 & 1,65 & 1,65 & 1,65 & 1,65 \\
\hline $\mathrm{t}_{0,01}$ & 2,55 & 2,58 & 2,62 & 2,55 & 2,57 & 2,51 & 2,54 & 2,53 & 2,52 \\
\hline Conclusion & $\begin{array}{c}\mu 1>\mu 2 \\
(\mathrm{p}=0,01)\end{array}$ & $\begin{array}{c}\mu 1>\mu 2 \\
(\mathrm{p}=0,05)\end{array}$ & $\begin{array}{c}\mu 1>\mu 2 \\
(\mathrm{p}=0,01)\end{array}$ & $\begin{array}{c}\mu 1>\mu 2 \\
(\mathrm{p}=0,01)\end{array}$ & $\begin{array}{c}\mu 1<\mu 2 \\
(\mathrm{p}=0,01)\end{array}$ & $\begin{array}{c}\mu 1<\mu 2 \\
(\mathrm{p}=0,01)\end{array}$ & $\begin{array}{c}\mu 1<\mu 2 \\
(\mathrm{p}=0,05)\end{array}$ & $\begin{array}{c}\mu 1<\mu 2 \\
(\mathrm{p}=0,01)\end{array}$ & $\begin{array}{c}\mu 1<\mu 2 \\
(\mathrm{p}=0,01)\end{array}$ \\
\hline
\end{tabular}

Conclusion: According to the results of the study, there are reasons to state that in the process of acquiring professionalism, professionals of a separate military specialty (in our case, artillery officers) develop separate components of thinking and intelligence. So, we observe statistically significant differences in the development of mathematical, spatial and mnemonic thinking of artillery officers and the verbal thinking is more developed of humanity officers . Taking into consideration of multifunctional character of military and professional activity of representatives of Group 1 on the graph, we can obsereve a smooth profile without a significant expression of the theoretical or practical component of thinking $\left(\mu_{\text {the- }}\right.$ $\left.{ }_{\mathrm{or}}=10,17 ; \mu_{\mathrm{prac}}=10,49\right)$. The specific professional directions of the artillery officers determine the development of the practical component of thinking $\left(\mu_{\text {theor }}=8,91 ; \mu_{\text {prac }}=\right.$ 11,87). So the Intelligence Structure Test by Amthauer can be used for professional and psychological selection and while diagnostics of development level of thinking due to its components.

\section{REFERENCES}

1. Bodalev A.A. Stolin V.V. Avanesov V.S. The General Psychodiagnostics. - SP.: Publishing House «Rech'», 2000. $440 \mathrm{p}$.

2. Burlachuk L.F. The Dictionary of psychodiagnosis / 3 edition. - SP.: Peter, 2007. -688 p.

3.Artillery Course Training of the Armed Forces of Ukraine (artillery brigade (rocket artillery regiment), battalion, artillery squadron, artillery platoon, artillery gun). $-\mathrm{K}$. : PH «Varta», 2013. - $376 \mathrm{p}$.

4. Makarenko M.V. The technique of conducting of surveys and evaluation of individual neurodynamic properties of higher nervous activity // Phisiological Journal- 1999. - V. 45, № 4. $-124 \mathrm{p}$.

5. Pasichnyk I. D. The Psychology of Thinking: Manual/ I.D. Pasichnyk, R.V. Kalamazh, U.I. Nikitchuk. - Ostrog: PH of NU «Ostroh Academy», 2015. - 560 p.

6. Rules of Firing and Control of Land Arms of the Armed Forces of Ukraine (group, battalion, artillery squadron, artillery platoon, artillery gun). - K. : PH «Varta», 2018. $295 \mathrm{p}$.
7. Psychology : manual / Yu. L. Trofimov, V. V. Rybalka, P. A. Goncharuk and others. ; under pub.. Yu. L. Trofimov, - K. : Lybid, 1999. - P. 324-390.

8. Amthauer R. The Intelligence Structure Test / Yeliseev O.P. Workshop on the psychology of personality. - SP., 2003. P.342-370.

9. Rudenko V.M. Mathematical methods in psychology: manual / V.M. Rudenko, N.M. Rudenko. - K.: Akademvydav, 2009. $-384 \mathrm{p}$.

10. Yagupov V.V. Factors for the formation of the personality of a military professional [Electronic source] / V. V. Yagupov, O.V. Yagupova / Creative Pedagofy: Scient.-method. Journal / Academy of International Cooperation in Creative Pedagogy. - Vinnitsya, 2011. - № 1. - P. 120-125. - access mode: http://www.info-library.com.ua/libs/stattya/5735chinniki-stanovlennja-osobistosti-vijskovogo-profesionala.

11. Thomdike P., Hagen E. Measurement and evaluation in psychologyl and education. - N. Y, 1977. - $144 \mathrm{c}$. 